\title{
Cost effectiveness of incremental programmes for lowering serum cholesterol concentration: is individual intervention worth while?
}

\author{
Ivar Sønbø Kristiansen, Anne Elise Eggen, Dag S Thelle
}

\begin{abstract}
Objective-To evaluate the relative cost effectiveness of various cholesterol lowering programmes.

Design-Retrospective analysis.

Setting-Norwegian cholesterol lowering programme in Norwegian male population aged 40-49 $(n=200000)$, whose interventions comprise a population based promotion of healthier eating habits, dietary treatment (subjects with serum cholesterol concentration $6 \cdot 0-7.9 \mathrm{mmol} / \mathrm{l})$, and dietary and drug treatment combined (serum cholesterol concentration $\geqslant 8.0 \mathrm{mmol} / \mathrm{l}$ ).
\end{abstract}

Main outcome measure-Marginal cost effectiveness ratios - that is, the ratio of net treatment costs (cost of treatment minus savings in treatment costs for coronary heart disease) to life years gained and to quality of life years (QALYs) saved.

Results-The cost per life year gained over 20 years of a population based strategy was projected to be $£ 12$. For an individual strategy based on dietary treatment the cost was about $£ 12400$ per life year gained and $\$ 111600$ if drugs were added for $50 \%$ of the subjects with serum cholesterol concentrations $\geqslant 8.0 \mathrm{mmol} / 1$.

Conclusions - The results underline the importance of marginal cost effectiveness analyses for incremental programmes of health care. The calculations of QALYs, though speculative, indicate that individual intervention should be implemented cautiously and within more selected groups than currently recommended. Drugs should be reserved for subjects with genetic hypercholesterolaemia or who are otherwise at very high risk of arteriosclerotic disease.

\section{Introduction}

Coronary heart disease represents an important health problem in most industrialised countries. There is strong evidence that lowering serum cholesterol concentration will reduce the incidence of the disease. ${ }^{1-4}$ Three strategies are available to do so: population based promotion of better eating habits, individual dietary treatment, and diet combined with various drugs. The individual approaches are based on the Norwegian cholesterol lowering programme, which recommends cholesterol testing and subsequent follow up by family doctors or medical specialists and accords with the American national cholesterol education programme, ${ }^{6}$ although it places less emphasis on analyses of high density liproprotein cholesterol and lipoprotein concentrations.

Though available analyses of cost effectiveness ${ }^{-13}$ indicate that lowering serum cholesterol concentration compares well with other generally accepted medical practices, they have presented average cost effectiveness ratios rather than incremental ones. In this study we calculate the marginal ratios of the three main strategies, discuss the quality of life aspects of these strategies, and demonstrate the relevance to policy of marginal analysis.

\section{Methods}

After the method of Weinstein and Stason ${ }^{14}$ we measured the cost effectiveness of a programme as the ratio of net treatment costs (cost of treatment minus savings in the cost of treating coronary heart disease to life years gained. As a model we used the Norwegian cholesterol lowering programme ${ }^{515}$ applied to the Norwegian male population aged $40-49$ years ( $n=$ 200000 ). We assumed full participation in the programme and compliance with the prescribed treatment and a distribution of serum cholesterol concentration (table I) similar to that in the Troms $\emptyset$ heart study population (E Arnesen, personal communication; see table I).

\section{INTERVENTION}

The population approach, entailing different forms of promoting healthy eating habits, is considered to be the first step in lowering serum cholesterol concentration. The Norwegian nutrition policy, which is explicitly directed at health aspects, is based on two
Institute of Community Medicine, University of Troms $\varnothing$, Postuttak, N-9000 Troms $\varnothing$, Norway

Ivar Sønbø Kristiansen, MD, assistant professor

Anne Elise Eggen, MSC

PHARM, research associate

Dag S Thelle, MD, professor

Correspondence to: $\mathrm{Dr}$ Kristiansen.

$B M 7$ 1991;302:1119-22

TABLE I-Fatal and non-fatal myocardial infarctions during first and subsequent 10 years of intervention in men aged $40-49$ at start of intervention by serum cholesterol concentration

\begin{tabular}{|c|c|c|c|c|c|c|c|c|c|}
\hline \multirow[b]{3}{*}{ Serum cholesterol } & \multirow[b]{3}{*}{ No of men } & \multirow{2}{*}{\multicolumn{2}{|c|}{$\begin{array}{l}\text { Unchanged incidence } \\
\text { of infarctions }\end{array}$}} & \multicolumn{6}{|c|}{ Reduced incidence of infarctions } \\
\hline & & & & \multicolumn{2}{|c|}{ Population strategy } & \multicolumn{2}{|c|}{ Dietary treatment } & \multicolumn{2}{|c|}{ Dietary and drug treatments } \\
\hline & & Non-fatal & Fatal & Non-fatal & Fatal & Non-fatal & Fatal & Non-fatal & Fatal \\
\hline \multicolumn{10}{|c|}{ First 10 years' intervention } \\
\hline$\leqslant 4 \cdot 9$ & 40000 & & & & & & & & \\
\hline $5 \cdot 0-5 \cdot 9$ & 40000 & 640 & 320 & 64 & 32 & 128 & 64 & 128 & 64 \\
\hline $6 \cdot 0-6 \cdot 9$ & 70000 & 1960 & 980 & 245 & 123 & 490 & 245 & 490 & 245 \\
\hline $7 \cdot 0-7 \cdot 9$ & 30000 & 1240 & 620 & 155 & 78 & 310 & 155 & 310 & 155 \\
\hline$\geqslant 8 \cdot 0$ & 20000 & 1226 & 614 & 184 & 92 & 368 & 184 & 552 & 276 \\
\hline Total & 200000 & 5066 & 2534 & 648 & 325 & 1296 & 648 & 1480 & 740 \\
\hline \multicolumn{10}{|c|}{ Subsequent 10 years' intervention } \\
\hline$\leqslant 4 \cdot 9$ & 40000 & & & & & & & & \\
\hline $5 \cdot 0-5 \cdot 9$ & 40000 & 1920 & 960 & 192 & 96 & 384 & 192 & 384 & 192 \\
\hline $6 \cdot 0-6 \cdot 9$ & 70000 & 5880 & 2940 & 735 & 369 & 1470 & 735 & 1470 & 735 \\
\hline $7 \cdot 0-7 \cdot 9$ & 30000 & 3720 & 1860 & 465 & 234 & 930 & 465 & 930 & 465 \\
\hline$\geqslant 8 \cdot 0$ & 20000 & 3678 & 1842 & 552 & 276 & 1104 & 552 & 1656 & 828 \\
\hline Total & 200000 & 15198 & 7602 & 1944 & 975 & 3888 & 1944 & 4440 & 2220 \\
\hline
\end{tabular}


government white papers. The Norwegian Nutrition Council has an important role as a broker of information among the scientific community, the agricultural sector, the food industry, and health authorities, as well as schools and the general public. The impact on eating habits may be enforced by a more targeted use of the mass media as well as through levying taxes on fatty foods or subsidising low fat foods.

The next step in lowering serum cholesterol concentration is screening for hypercholesterolaemia and following up subjects whose serum values exceed certain defined limits. The Norwegian programme defines any person with a serum cholesterol concentration $>5.0 \mathrm{mmol} / \mathrm{l}$ as being at risk of premature death and recommends a confirmatory cholesterol test. If the average value of the two tests is $5 \cdot 0-5 \cdot 9 \mathrm{mmol} / \mathrm{l}$ a new test should be performed in five years. Above this concentration dietary treatment is recommended, with visits to the doctor and additional blood sampling at intervals depending on the actual value. We assumed 1.5 visits a year for subjects with a serum cholesterol concentration of $6 \cdot 0-7.9 \mathrm{mmol} / \mathrm{l}$ and 2.0 visits a year above this value. Visits involving cholesterol testing would be somewhat more frequent in the first two years of the programme. This represents fewer visits and tests than the recommendations in the American programme, ${ }^{6}$ and it does not include the more expensive lipoprotein analyses.

The possible third step is the use of drugs in combination with dietary treatment for subjects with the highest risk. We did not consider any specific drug but assumed that half of all subjects with an initial concentration $\geqslant 8.0 \mathrm{mmol} / 1$ would be prescribed a lipid lowering drug - that is, about $5 \%$ of the population, which is in line with experience in the United States. ${ }^{16}$ The prescription of drugs would necessitate an extra visit by the doctor each year. To cover side effects we included additionally 0.3 extra visits and four blood tests a year.

\section{CONSEQUENCES FOR HEALTH}

We assumed that a systematic population programme leads to $5 \%$ lower cholesterol concentrations, but the evidence is sparse. The North Karelia project showed a $4 \%$ reduction $^{1-}$ and Norwegian studies a $5 \%$ reduction. ${ }^{18}$ We further assumed that individual counselling on diet in combination with the population strategy would accomplish a total reduction of cholesterol concentration by $10 \% .^{1219}$ Traditional cholesterol lowering agents reduce cholesterol concentration by $15-20 \%$ and the new statins somewhat more..$^{20}$ In this study we assumed an average reduction of $20 \%$ by diet and drugs combined.

A $2 \%$ reduction in the incidence of coronary heart disease is normally assumed when serum cholesterol concentration is reduced by $1 \% .^{25}$ This may be too conservative. Consequently, we assumed that a $1 \%$ reduction in serum cholesterol reduces the risk of the disease by $2 \%$ at concentrations of $5 \cdot 0-5 \cdot 9 \mathrm{mmol} / \mathrm{l}$, by $2 \cdot 5 \%$ at $6 \cdot 0-7 \cdot 9 \mathrm{mmol} / \mathrm{l}$, and by $3 \%$ above $7 \cdot 9 \mathrm{mmol} / \mathrm{l}$. The number of myocardial infarctions at different lipid concentrations was based on a 10 year follow up of 3725 men aged 40-49. ${ }^{21}$ We further assumed that a third of myocardial infarctions were fatal (table I). ${ }^{21}$ The gradually increasing effect of cholesterol lowering might be expected to start three years after the onset of the programme. ${ }^{23}$ We used the causes of death statistics ${ }^{22}$ to assume a threefold increase in myocardial infarctions when the programme was followed over the subsequent 10 years. To calculate the number of life years saved we assumed that all myocardial infarctions in the first 10 years occurred in year 7 and those in the subsequent 10 years in year 15 .

A reduced serum cholesterol concentration presumably reduces the number of coronary artery bypass graft operations for angina pectoris. The extent of this reduction was estimated from records of the total number of such operations in Norway.

\section{ESTIMATING COSTS}

We followed Weinstein's approach for costing, ${ }^{14}$ and, as with Williams's analysis of coronary artery bypass grafting,$^{23}$ we considered only health care costs. The different cost components were based on current fee schedules or recent cost calculations (table II). As we lacked other data these charges were used even if they only approximate to actual consumption of resources. ${ }^{24}$ To calculate resource savings owing to avoided myocardial infarctions we used data specific to myocardial infarctions for average hospital costs in Norway $^{25}$ and assumed that a quarter of patients with fatal myocardial infarctions would be admitted to hospital. Avoided costs of treatment after infarction with $\beta$ blockers were estimated, as were increased costs associated with use of health care as a result of increased life expectancy (table II).

TABLE II-Cost components of lowering serum cholesterol concentration

\begin{tabular}{llr}
\hline Component & Unit of cost & Cost $(\mathfrak{l})$ \\
\hline Screening & Per individual & $6 \cdot 40$ \\
Confirmatory screening test & Per individual & $3 \cdot 20$ \\
Doctor's visit & Per visit & $16 \cdot 20$ \\
Cholesterol testing & Per test & $2 \cdot 30$ \\
$\begin{array}{l}\text { Treatment of coronary heart } \\
\text { disease }\end{array}$ & Per hospital stay & $2318 \cdot 00$ \\
$\begin{array}{l}\text { Coronary artery bypass } \\
\text { grafting }\end{array}$ & Per operation & $9922 \cdot 00$ \\
$\begin{array}{l}\text { Treatment after infarction } \\
\text { Average health care cost }\end{array}$ & Per person per year & $227 \cdot 00$ \\
Drugs & Per person per year & $455 \cdot 00$ \\
Population strategy & Per person per year & $909 \cdot 00$ \\
& Per year & $454545 \cdot 00$ \\
\hline
\end{tabular}

With respect to the population strategy the annual budget of the Norwegian Nutrition Council is about $£ 450000$. We assumed that a stronger commitment to health education programmes in schools and the increased use of the mass media would cost ten times as much - that is, about $£ 4.5 \mathrm{~m}$ per year. We allocated $10 \%$ of this amount to our target group (men aged 40 49).

\section{QUALITY OF LIFE}

As, to our knowledge, no analyses of quality of life have been performed in this field (individual intervention in asymptomatic subjects) we arbitrarily assumed that quality of life is reduced by $0 \cdot 2 \%$ when a subject is identified as being at risk of premature death and included in the individual intervention programme (serum cholesterol concentration $>5.0 \mathrm{mmol} / \mathrm{l}$ ). The reduction is conceivably greater (say $0.5 \%$ ) when the risk is such that drugs are prescribed. The gain in quality of life was assumed to be $10 \%$ for a non-fatal myocardial infarction avoided ${ }^{26}$ and $100 \%$ for a death avoided. Future costs and benefits were discounted according to normal practice ${ }^{1+27}$ at a rate of $7 \%$, that recommended by the Norwegian Treasury.

\section{Results}

The discounted total net cost of the population strategy was estimated at $£ 36700$ ( $\mathrm{Kr} 136836$ in 1990 ) with a gain of 3100 discounted life years, giving a cost effectiveness ratio of $£ 12$ for men aged $40-49$ at entry to the programme (table III). The incremental cost of cholesterol screening and individual dietary treatment was $£ 38.8 \mathrm{~m}$, increasing to $£ 99.2 \mathrm{~m}$ when drug treatment was added. The incremental life years gained were 3100 years and 900 years for dietary treatment and drug treatment respectively. Hence the marginal cost effectiveness ratios were about $£ 12400$ 
for dietary treatment and about $\$ 111500$ for the combined dietary and drug treatment modality. As women have about the same serum cholesterol concentrations as men but less than a fifth the risk for coronary heart disease the cost effectiveness ratios for women are at least five times higher.

TABLE III - Marginal cost effectiveness ratios (cost $£$ ) per life year and per quality of life year ( $Q A L Y)$ for men aged 40-49 at entry into cholesterol lowering programme

\begin{tabular}{lrr}
\hline Strategy & Life year & QALY \\
\hline No action & 0 & 0 \\
Population approach & 12 & 10 \\
Dietary treatment & $12440^{\circ}$ & 100546 \\
Dietary and drug treatments & 111549 & 125860 \\
\hline
\end{tabular}

The population approach represented a gain of 3800 quality of life years (QALYs) ( $£ 10$ per QALY, table III). The net incremental effects of dietary treatment were 400 QALYs ( $£ 100500$ per QALY) and 800 QALYs ( $£ 125900$ per QALY) for drug treatment. If the reduction in quality of life were only $0 \cdot 1 \%$ by individual interventions the net incremental gains in QALYs would be about 2100 and 700 QALYs for diet and drugs respectively. If the reduction were $1 \%$ the individual interventions would represent substantial net losses of QALYs.

We performed a sensitivity analysis of factors most crucial to the conclusions (table IV). Overall the cost effectiveness ratios were fairly robust to realistic changes in the assumptions on which the analysis is based.

TABLE IV - Sensitivity analysis: cost per life year gained under different assumptions for men aged 40-49

\begin{tabular}{|c|c|c|c|c|c|c|c|c|}
\hline \multirow[b]{3}{*}{ Assumption } & & & \multicolumn{6}{|c|}{ Marginal cost effectiveness ratio ( $£ 1000)$} \\
\hline & \multicolumn{2}{|c|}{ Estimate $(£)$} & \multicolumn{2}{|c|}{$\begin{array}{l}\text { Population } \\
\text { approach }\end{array}$} & \multicolumn{2}{|c|}{ Dietary treatment } & \multicolumn{2}{|c|}{$\begin{array}{l}\text { Dietary and drug } \\
\text { treatments }\end{array}$} \\
\hline & Low & High & Low & High & Low & High & Low & High \\
\hline Baseline & & & \multicolumn{2}{|c|}{0} & \multicolumn{2}{|c|}{13} & \multicolumn{2}{|c|}{112} \\
\hline Cost per visit & 14 & 27 & 0 & 0 & 11 & 20 & 111 & 113 \\
\hline Cost per screening & 5 & 14 & 0 & 0 & 12 & 13 & 112 & 112 \\
\hline Health care cost per year & 0 & 363 & $-0 \cdot 5$ & $0 \cdot 2$ & 12 & 13 & 111 & 112 \\
\hline Cost of drugs & 455 & 1363 & 0 & 0 & 13 & 13 & 57 & 166 \\
\hline Discount rate (\%) & 0 & 10 & $-0 \cdot 2$ & $0 \cdot 2$ & 8 & 16 & 72 & 136 \\
\hline Life year gain & $+20 \%$ & $-20 \%$ & $-0 \cdot 2$ & $0 \cdot 4$ & 10 & 16 & 93 & 140 \\
\hline Mass strategy cost & 181800 & 909100 & -0.9 & 1.6 & 13 & 13 & 112 & 112 \\
\hline
\end{tabular}

\section{Discussion \\ COSTS}

As recommended by Weinstein ${ }^{14}$ we did not include the production effects of the programmes, nor did we include time costs incurred by patients - for example, in doctor's visits. Thus the analysis is concerned solely with health services cost per QALY (and per life year) as shown earlier by Williams. ${ }^{23}$ In general, cost components were estimated conservatively; cost savings are likely if anything to be exaggerated.

\section{CONSEQUENCES FOR HEALTH}

We assumed that dietary treatment would have a smaller effect on cholesterol concentration than was assumed in a recent British report. ${ }^{13}$ However, our assumptions accord with large scale intervention trials. ${ }^{1219}$ There is much uncertainty in estimating the long term effects of lowering cholesterol concentration, particularly among women. Lack of available data meant that we could not include the potential effects on cerebral strokes and intermittent claudication. The inclusion of such data, however, would alter the estimates of cost per life year gained little as the mortality from these diseases is low in this age group. ${ }^{22}$

The assumption of full participation and compliance with the programme is not realistic. Though anything less would reduce the costs as well as the benefits, it would probably make the cost effectiveness ratios less favourable as these problems are most likely to occur in the high risk group, in which the potential benefit is greatest. Further, the estimates of cholesterol lowering through dietary treatment may be too optimistic.

For angina pectoris we considered only a reduced amount of coronary surgery. Cholesterol lowering may also mean a lower incidence of less severe angina, but the impact of including this would not have affected the cost effectiveness ratios much.

\section{COST EFFECTIVENESS}

As with other economic studies our analysis is based on numerous assumptions. Hence the calculated costs per life year and per QALY are approximate. They are comparable, however, to other studies on the average cost effectiveness of different approaches for cholesterol lowering..$^{7-13}$ When the potential for implementing cholesterol lowering programmes stepwise is examined, however, a somewhat different picture emerges. The cost per life year saved by the mass strategy is negligible. However, the extra (marginal) cost of dietary treatment is substantial compared with the extra life years saved and that for drug treatment is even more so. The analysis clearly shows the importance of a marginal analysis when incremental programmes are available.

Furthermore, individual intervention as recommended by the Norwegian programme seems to be less cost effective than curative measures for coronary heart disease..$^{232829}$

\section{QALYS}

The Norwegian programme implies that some 160000 men aged 40-49 would be included for individual intervention of various degrees. Yet only a few have coronary symptoms at entry to the intervention, and some 30-40000 will develop symptoms during the subsequent 20 years. This means that more than half of the middle aged male population will "unnecessarily" be labelled as subjects at risk. To what extent this labelling detracts from their quality of life is not known, although some indications are evident. ${ }^{3031}$ Avoiding death certainly means an increase in QALYs. Overall, our assumption of a $0 \cdot 2 \%$ reduction in life quality through risk identification, though controversial, seems justified.

\section{CHOLESTEROL LOWERING POLICIES}

The mass strategy for cholesterol lowering seems to be highly cost effective and also acceptable ethically. It may also prevent coronary heart disease in low risk groups which are excluded from the individual programmes. ${ }^{32}$

The individual intervention for men through testing and diet counselling may be comparable with established health care programmes in terms of cost per life year gained. However, ethical and clinical problems exist as the potential long term negative effects of identification of risk have not been studied. Intervention may also counteract the mass strategy in population groups with moderately increased serum cholesterol concentration $(5 \cdot 0-6 \cdot 5 \mathrm{mmol} / \mathrm{l})$. Kinley and Heller reported that subjects with serum cholesterol concentrations $<6.5 \mathrm{mmol} / 1$ on screening may believe that their diet is optimal when the test result is all right. ${ }^{33}$ The use of drugs with liberally defined indications emerges from our figures as being less cost effective than most other programmes in health care. With a lack of knowledge of the long term effects the ethical issues loom large. Consequently, it would be prudent to reserve such treatment for very high risk groups, and it may be relevant to recall experience with hypertension. There is now evidence that drugs that 
were widely used for mild hypertension in the $1960 \mathrm{~s}$ and ' $70 \mathrm{~s}$ might have done more harm than good, ${ }^{3+2}$ and this mistake may be potentially repeated in subjects with hypercholesterolaemia.

Doubts are even stronger in women: firstly, the effect of cholesterol lowering remains to be shown and, secondly, the incidence of coronary heart disease is already very low in middle aged women.

Further studies of the long term effects of individual intervention on both biological processes and quality of life are needed, especially for women and other low risk groups. In the mean time it is prudent to recall that a high serum cholesterol concentration is caused by unhealthy eating habits. Our analysis above indicates that individual interventions should be implemented with great caution. The widely recommended intervention limits ${ }^{560}$ should be adjusted to include only a small proportion of the population. To what extent women should be included in such programmes is unclear. The use of drugs should be reserved for subjects with genetic hypercholesterolaemia or those who are otherwise at very high risk of arteriosclerotic disease.

We thank Anne Brit Westerheim, Per Maehlumshagen, and Gavin Mooney for their valuable contributions.

\footnotetext{
1 Hjermann I, Holme I, Leren P. Effect of diet and smoking intervention on the incidence of CHD. Lancet 1981;ii:1303-10.

2 incidence of CHD. Lancet 1981;11:1303-10. Reduction in incidence of coronary heart disease. FA.11A 1984:251:351-64. The Lipid Research Clinics Coronary Primary Prevention Trial results. II The Lipid Research Clinics Coronary Primary Prevention Trial results. II
The relationship of reduction in incidence of coronary heart disease to The relationship of reduction in incidence of
cholesterol lowering. F $A M A$ 1984;251:365-74.

cholesterol lowering. 7 AMA 1984:251:365-74.
+ Frick MH, Elo O, Haapa K, Heinonen OP, Heinsalmi P, Helo P. Helsinki heart study: primary prevention trial with gemfibrozil in middle-aged men with dyslipidemia. N Engl f Med 1987;317:1237-45

5 Bjartveit $\mathrm{K}$, Blomhoff JP, Drevon CA, et al. A cholesterol lowering programm for the adult population. Tidsskr Nor Lacgeforen 1988;108:2285-8. (In Norwegian.)

6 NCEP: Report of the national cholesterol education program expert panel on detection, evaluation, and treatment of high blood cholesterol in adults. Arch Intern Med 1988;148:36-69.

7 Weinstein MC Cost-effectiveness of interventions to prevent or treat coronary heart disease. Annu Rer Public Health 1985;6:41-63.

8 Oster G, Epstein AM. Primary prevention of coronary heart disease: the economic henefits of lowering serum cholesterol. Am f Public Health 1986:76:647-56.

9 Oster G, Epstein AM. Cost-effectiveness of antihyperlipemic therapy in the prevention of coronary heart disease. $\mathcal{F} A$.MA 1987;258:2381-7.

10 Hall JP. A cost-cffectiveness analysis of alternative strategies for the prevention of heart disease. Med F A ust 1988;148:273-7.

11 Kinosian BP, Eisenberg JM. Cutting into cholesterol. FAMA 1988;259: 2249-54.
}

\section{Microvascular vasodilatation in feet of newly diagnosed non-insulin dependent diabetic patients}

\section{Diabetes Research \\ Laboratories, Postgraduate \\ Medical School, University of Exeter, Exeter EX2 5DW D D Sandeman, MRCP,} research registrar

C A Pym, RGN, research nurse E M Green, BSC, research nurse

C Seamark, MRCGP, clinical assistant

A C Shore, PHD, research fellow

$\mathrm{J}$ E Tooke, MRCP, senior

lecturer in medicine

Correspondence to:
Dr Sandeman.

BMF 1991;302:1122-3
12 Martens LI, Rutten FFH, Erkelens 1)W, Ascoop CAPL. Cost effectiveness of cholesterol-lowering therapy in the Netherlands. Am F. Med 1989;87 suppl $4 \mathrm{~A}: 5+-8$

13 Standing Medical Advisory Committee to the Secretary of State for Health. The cost-effectiveness of opportunistic cholesterol testing. London: SMAC, 1990. 4 Weinstein MC, Stason WB. Foundations of cost-effectiveness analvsis for health and medical practices. $N$ Engl 7 Med 1977;296:716-21

15 Eggen AE, Michlumshagen PM, Westerheim AB, Kristiansen IS. Economical analysis of a cholesterol lowering program. Tidsskr Nor Leceforin 1989:109: 857-63. In Norwegian

16 Wrsowski DK, Kennedy DL, (iross TP. Prescribed use of cholesterollowering drugs in the United States, 1978 through 1988. F. .1. 1990;263: 2185-8

17 Salonen JT, Puska P, Kottke TE, et al. Changes in smoking, serum cholesterol and blood pressure levels during a community-based cardiovascular disease prevention program - the North Karelia project. Am F Epidemiol 1981;114 $81-9+$

18 National Health Screening Service. The cardiovascular disease study in Norevegian counties-results from the second screening. Oslo: National Health Screening Service, 1988

19 Multiple Risk Factor Intervention Trial. Risk factor changes and mortality results. F.A.114 1982:248:1+65-77

20 Stein EA. Management of hypercholesterolemia. Am F.Med 1989;87 suppl HA : $20-27 \mathrm{~S}$.

21 W'estlund $\mathrm{K}$, Nicholaysen $\mathrm{R}$. Ten-vear mortality and morbidity related to serum cholesterol. Scand f Clin Lab Invest 1972:30 (suppl 127):3-24.

22 Central Bureau of Statistics. Causes of death 1985. Oslo: Central Bureau of Statistics, 1986.

23 Williams A. Economics of coronary artery hypass grafting. BMY 1985;291: 326-9.

24 Finkler SA. The distinction between cost and charges. Ann Intern Med 1982;96:102-9.

25 Slattebrekk OV. Cost per patient based on DR(j-classification. Trondheim: Norwegian Institute of Hospital Research, 1990, Report STF-81-A90003. In Norwegian.

26 Read JL, Quinn RJ, Berwick DM, Fineberg HV, Weinstein MC. Preferences for health outcomes. Med Decis. Making 1984;4:315-29.

27 Weinstein MC, Fineberg HV. Clinical decision analysis. Philadelphia: Saunders, 1980

28 Weinstein MC, Stason WB. Cost-effectiveness of coronary arterv hipass surgerv. (irculation 1982;66 (suppl III):56-66.

29 Goldman L, Sia STB, Cook EF, et al. Costs and effectiveness of routine therapy with long term beta-adrenergic antagonists after acute myocardial infarction. N Fingl f Med 1988:319:152-7.

30 Bloom JR, Monterossa S. Hypertension labeling and sense of well-being. A $m$ f Public Health 1981;71:1228-32.

31 Stoate HG. Can health screening damage vour health? I $R$ Coll (ien Pract $1989 ; 39: 193-5$.

32 Goldman L, Weinstein MC, Williams LW. Relative impact of targeted versus populationwide cholesterol interventions on the incidence of coronary hear disease. Circulation 1989;80:254-60.

33 Kinley $S$, Heller RF. Effectiveness and hazards of case finding for a high cholesterol concentration. BMY 1990;300:1545-7.

34 Holme I. Drug treatment of mild hypertension to reduce the risk of (CHD): Is it worth-while? Stat Med 1988;7:1 109-20.

35 Thurmer H, Lund-Larsen PG, Tverdal A, Thelle DS. Treatment of hypertension as a risk factor in a prospective study. International fournal of Risk and Safetv in Medicine 1991;1:267-78.

36 European Atherosclerosis Society. The recognition and management of hyperlipidaemia in adults: a policy statement of the European Atherosclerosis Society. Eur Heart f 1988;9:571-600.

Accepted 12 March 1991)

diabetic subjects without significant large vessel disease and compared the results with those from healthy controls and insulin dependent diabetic subjects.

\section{Patients, methods, and results}

Nine non-insulin dependent diabetic patients (assessed on clinical grounds) were recruited from successive referrals to our clinic (four women, five men, median age 42 (range 25-60) years. Controls matched for age and sex (hospital staff with no medical history, mean age 40 (25-60)) and insulin dependent diabetic patients matched for age and sex (mean age 42 (25-60), median duration of diabetes $19(2-48)$ years) were recruited for comparison. Hypertensive subjects, those taking vasoactive drugs, and those with large vessel disease (indicated by a previous vascular event, ankle systolic index $<0 \cdot 1$, or absent foot pulses) were excluded.

Brachial systolic blood pressure was higher in the insulin dependent patients than in the non-insulin dependent patients or the controls (median 144 (112$160) \mathrm{mm} \mathrm{Hg}, 126(105-170) \mathrm{mm} \mathrm{Hg}$, and 120 (106-140) $\mathrm{mm} \mathrm{Hg}$, respectively; $\mathrm{p}<0.05)$, although no difference in systolic pressure taken at the ankle or brachial diastolic pressure was found. Ambient blood glucose An impairment of this response has been shown in type I (insulin dependent) diabetes. ${ }^{2}$ We examined the integrity of this response in non-insulin dependent 